\title{
STOICHIOMETRY AND PLANKTONIC GRAZER COMPOSITION OVER GRADIENTS OF LIGHT, NUTRIENTS, AND PREDATION RISK
}

\author{
Spencer R. Hall, ${ }^{1,3}$ Mathew A. Leibold, ${ }^{1,4}$ David A. Lytle, ${ }^{1,5}$ And Val H. Smith ${ }^{2}$ \\ ${ }^{1}$ Department of Ecology and Evolution, University of Chicago, 1101 E. 57th Street Chicago, Illinois 60637 USA \\ ${ }^{2}$ Program in Ecology and Population Biology, Department of Ecology and Evolutionary Biology, University of Kansas, \\ Lawrence, Kansas 66045 USA
}

\begin{abstract}
Mechanisms that explain shifts in species composition over environmental gradients continue to intrigue ecologists. Ecological stoichiometry has recently provided a new potential mechanism linking resource (light and nutrient) supply gradients to grazer performance via elemental food-quality mechanisms. More specifically, it predicts that light and nutrient gradients should determine the relative dominance of P-rich taxa, such as Daphnia, in grazer assemblages. We tested this hypothesis in pond mesocosms (cattle tanks) by creating gradients of resource supply and predation risk, to which we added diverse assemblages of algal producer and zooplankton grazer species. We then characterized the end-point composition of grazer assemblages and quantity and elemental food quality of edible algae. We found that somatically P-rich Daphnia only dominated grazer assemblages in high-nutrient, no-predator treatments. In these ecosystems, $\mathrm{P}$ sequestered in producers exceeded a critical concentration. However, other grazers having even higher body $\mathrm{P}$ content did not respond similarly. These grazers were often abundant in low-nutrient environments with poorer food quality. At face value, this result is problematic for ecological stoichiometry because body composition did not correctly predict response of these other species. However, two potential explanations could maintain consistency with stoichiometric principles: species could differentially use a high-P resource (bacteria), or body composition might not always directly correlate with nutrient demands of grazers. Although our data cannot differentiate between these explanations, both suggest potential avenues for future empirical and theoretical study.
\end{abstract}

Key words: Daphnia; grazers; light; nutrients; phosphorus; predation; predation-risk gradients, resource-supply gradients; species composition, explaining shifts in; stoichiometry; zooplankton.

\section{INTRODUCTION}

Ecologists remain challenged to mechanistically explain changes in species composition over environmental gradients. In planktonic systems, "resource-ratio" (Tilman 1982, Huisman and Weissing 1995, Grover 1997) and "keystone predation" (Leibold 1996, Grover 1997) models predict changes in species composition along productivity gradients. Ecological stoichiometry has produced a third hypothesis. It forecasts shifts in grazer composition over gradients of light and nutrient supply to ecosystems (Sterner et al. 1997, Sterner and Elser 2002). Specifically, it predicts that grazer species with high somatic phosphorus content should dominate high-nutrient, low-light ecosystems that produce good elemental food quality, while grazers

Manuscript received 14 July 2003; revised 23 January 2004; accepted 26 January 2004. Corresponding Editor: D. A. Spiller.

${ }^{3}$ Present address: Kellogg Biological Station, 3700 E. Gull Lake Drive, Hickory Corners, Michigan 49060 USA. E-mail: srhall@uiuc.edu

${ }^{4}$ Present address: Section of Integrative Biology, University of Texas, 1 University Station C0930, Austin, Texas 78712 USA.

${ }^{5}$ Present address: Department of Zoology, Oregon State University, Corvallis, Oregon 97331 USA. with low-nutrient bodies should dominate low-nutrient, high-light ecosystems where food quality is poorer.

These predictions emerge from several key premises. The first is that both producers (plants) and grazers are packages of carbon and elemental nutrients, such as nitrogen and phosphorus. However, producers and grazers often differ in the ratio at which, say, carbon (C) and phosphorus (P) are packaged. In the laboratory and nature, primary producers are plastic in their $\mathrm{P}$ content (Andersen 1997, Sterner et al. 1997, Elser et al. 2000, Hessen et al. 2002), and much of this variation may be driven by (relative) supply of light and nutrients to ecosystems ("light:nutrient hypothesis"; Sterner et al. 1997).

Second, this variation in nutrient content of producers, driven by relative supplies of light and nutrients, can impact growth rates of grazers such as Daphnia. In contrast to producers, Daphnia typically has high average $\mathrm{P}$ content, but its body composition is much less plastic (it is almost homeostatic; Andersen and Hessen 1991, DeMott et al. 1998). Thus, Daphnia requires algal food of high P content (or high "elemental quality") to grow optimally. When Daphnia consumes phosphorus-poor food, imbalances between the nutrient content of its food and its own body become important-Daphnia growth and reproduction may become 
nutrient limited (Sterner 1993, 1994, Urabe and Sterner 1996, Sterner et al. 1998, Elser et al. 2001). Furthermore, these mismatches may be common in nature (Elser et al. 2000).

Third, the elemental composition of zooplankton varies among grazer taxa. Some genera have higher and some have lower P content than Daphnia (Andersen and Hessen 1991). Grazers with high P content generally have high maximal growth rates (reflecting their high ribosomal RNA content; Elser et al. 1996) and also should be sensitive to P content of their food. Grazers with lower body P content should be less prone to nutrient limitation but have lower maximal growth rates (Urabe and Watanabe 1992, DeMott et al. 1998, Sterner and Elser 2002). Thus, in ecosystems with high light supply relative to nutrients, species that grow well when food quality is poor should dominate herbivore assemblages. In contrast, high elemental food quality in ecosystems receiving high nutrient:light supply ratios should allow P-rich herbivores to grow efficiently and become dominant through their growth-rate advantage (Elser et al. 1996, Main et al. 1997).

In an enclosure experiment, Urabe et al. (2002) have shown supporting evidence for this hypothesis: both food quality and Daphnia's dominance of a local grazer assemblage increased with nutrient additions to lownutrient, lake mesocosms. This field experiment was encouraging because it involved multiple species of grazers and producers and was conducted in semi-natural conditions. However, it was a short-term, local experiment and documented response of a closed species assemblage to light and nutrient perturbations. Consequently, it did not allow for arrivals of new species from the regional species pool. These arrivals could have affected the long-term outcome of the experiment (Leibold et al. 1997). In fact, results from similar short-term, local experiments may depend sensitively on time allowed for colonization by new species and for extinction of inferior competitors (Leibold et al. 1997).

In this study we used a different experimental approach that incorporated regional species pools and longer time scales. In a series of replicated pond mesocosms, we manipulated nutrients (by increasing total supply and altering N:P ratios) and light (using shade cloth), but also varied predation risk of zooplankton by adding an invertebrate predator. Throughout the experiment, we periodically added diverse assemblages of producers and grazers collected from natural ponds spanning wide gradients of light and nutrient supply. Presumably, these introductions eliminated time needed for colonization by new species. Furthermore, we added a wide diversity of algal species that should have varied extensively in their interspecific resistance to grazing, digestibility, and competitive ability (Leibold 1989, Grover 1997, DeMott and Tessier 2002). It seems possible that such variability could weaken the light: nutrient hypothesis by leading to parallel changes in plant composition. We added a very diverse assemblage of grazer species that varied not only in $\mathrm{P}$ content but also susceptibility to predators. Variability in resistance to predation is known to affect species composition over resource gradients (Leibold 1996, Grover 1997).

Ecological stoichiometry predicts (1) increases in Prelated food quality (i.e., lower C:P ratios) of edible algal producers as the supply rate of nutrients increases and/or light availability decreases, and (2) dominance of P-rich grazers such as Daphnia spp. only in ecosystems containing high-quality food and low predation risk (if susceptible to predators). In this study we created a food-quality gradient, which was driven at least in part by experimentally manipulated supply of light and nutrients. We then documented dominance by P-rich Daphnia along this food-quality gradient. Daphnia dominated ecosystems containing good elemental food quality and low predation risk, but not in environments with poor food quality. Both of these findings support stoichiometric predictions. However, grazer taxa with even higher P content than Daphnia could dominate poor food-quality environments. We offer two explanations for these latter, counterintuitive results, implicating differential ability to eat bacteria and/ or reexamination of a grazer's nutrient demands.

\section{Methods}

\section{Experimental setup, sampling, and sample analysis}

We used a fully factorial experimental design to test the simultaneous effects of light availability, absolute nitrogen and phosphorus availability, relative $\mathrm{N}: \mathrm{P}$ availability, and trophic structure on zooplankton community composition. During May-June 2000 we created gradients of light and nutrient supply and predation risk in 300-L cattle tanks. To each tank we added silica sand substrate, well water, and inorganic nitrogen (N) and phosphorus (P) $\left(\mathrm{NaNO}_{3}\right.$ and $\mathrm{NaH}_{2} \mathrm{PO}_{4}$, respectively) to raise nutrient concentrations to target $\mathrm{N}: \mathrm{P}$ ratios (Ratio; 5:1, 14:1, and 50:1) and supply (Supply; high was $10 \times$ low) (see below). Also, we reduced light availability in half of the tanks (Light) by $90 \%$ using neutral shade cloth. We inoculated each mesocosm with diverse assemblages of algae and zooplankton at fortnightly intervals. These inoculae were collected along wide, natural light-nutrient gradients from local ponds (proximate to Kellogg Biological Station and within Barry and Middleville State Game Areas, Kalamazoo and Barry Counties, Michigan, USA). In plus-predator treatments (Trophic), we also added 12 adults of Notonecta undulata. Each cattle tank also received 30 Physa spp. snails and 30 Rana catesbeina tadpoles to graze and remineralize nutrients bound in benthic algae. These grazers maintained relatively low periphyton growth on the walls of the mesocosm (median: $2.64 \mathrm{mg}$ chl $a / \mathrm{m}^{2}$, interquartile range: $1.17-12.78$ $\mathrm{mg}$ chl $a / \mathrm{m}^{2}$; see Fig. 2 of Leibold and Wilbur [1992] for comparison without benthic grazers). Finally, we 
added nutrients weekly to approximately maintain target levels (total $\mathrm{N}$ and total P levels of 14 and 700, 25 and 370 , and 44 and 220 for 5:1, 14:1, and 50:1 Ratio treatments, respectively; "high" Supply treatments received $10 \times$ these levels) by assuming a $5 \% /$ day loss rate from the water column (M. A. Leibold and V. H. Smith, unpublished data). The factorial experimental design was

$$
\begin{gathered}
\text { Replicates }_{3-4}\left(\text { Ratio }_{3} \times \text { Supply Level }_{2} \times \text { Light }_{2}\right. \\
\left.\times \text { Trophic Structure }_{2}\right) .
\end{gathered}
$$

We sampled at the end of summer to characterize final composition of grazer assemblages and algal stoichiometry. We collected 8.5-L samples using tube samplers and a fixed sampling regime during three sampling periods: $15-17$ and 29-31 September and 19-21 October, but data from these samples were averaged before analyses. During each period the zooplankton samples were sieved through $88-\mu \mathrm{m}$ Nitex mesh and preserved in acid Lugol's solution. Zooplankton was identified and counted (Pennak 1978) to species for Daphnia and Simocephalus but to genus for all other taxa, and up to 25 individuals/species/sample were measured using a $40 \times$ dissecting scope and converted into dry mass using published length-mass regressions (McCauley 1984). Additionally, during the first sampling period only, we sieved water through $35-\mu \mathrm{m}$ mesh for subsequent $\mathrm{C}: \mathrm{P}$ analysis of the "edible" algal fraction (Cottingham 1999). We filtered edible seston (which is mostly algae but also contains any suspended detritus and bacteria) on pre-combusted, acid-rinsed $\mathrm{GF} / \mathrm{F}$ filters. We then dried $\left(60^{\circ} \mathrm{C}\right)$ one sample per mesocosm to measure $\mathrm{C}: \mathrm{N}$ content (Carlo-Ebra auto-analyzer), and froze $\left(-80^{\circ} \mathrm{C}\right)$ a second sample for particulate P measurements (APHA 1980, Prepas and Rigler 1982). We also measured biomass of "edible" $(<35$ $\mu \mathrm{m})$ algae using chlorophyll $a$ as a proxy (by extracting samples on GF/F filters in chilled ethanol [Webb et al. 1992] and by using narrow-band fluorimetry [Welschmeyer 1994]). To rank zooplankton taxa by body composition, we measured the particulate $\mathrm{P}$ content of 50$200 \mu \mathrm{g}$ dry mass from each of the nine major zooplankton taxa using the methods of DeMott et al. (1998). Animals were collected from environments in which they were abundant. The Daphnia and Simocephalus samples were collected from 10 and 3 separate mesocosms, respectively; for other taxa, we often lumped animals from different mesocosms/treatments to collect enough dry mass for analyses.

\section{Statistical analyses}

We analyzed the response of seston stoichiometry using nonparametric ANOVA. Before analysis we first transformed edible $\mathrm{C}, \mathrm{P}$, and $\mathrm{C}: \mathrm{P}$ to optimally reduce heteroscedasticity following Taylor (1961). Then we used Anderson's $(2001 a, b)$ approach to partition variation, which is described for balanced designs. To more readily implement her approach, we imposed balance on the experimental design (Eq. 1) by randomly eliminating one of the four replicates in each of the six high-nutrient, no-predator treatments, and then tested for significance of each factor using 9999 randomizations in Matlab 5.3 (MathWorks 1999). We set $\alpha=$ 0.0167 (i.e., $0.05 / 3$ ) to correct for the interrelated comparisons.

We analyzed $L$-shaped relationships between Daphnia abundance and C:P ratio and seston $\mathrm{P}$ (see Results) using tree regression (De'ath and Fabricius 2000). A regression-tree algorithm (SYSTAT 8.0; SPSS 1998) recursively split the explanatory variable into increasingly homogenous groups of Daphnia abundance. The final split point of the explanatory variable minimized within-group sum of squares.

The remaining analyses characterized response of zooplankton taxa to the experimental treatments. To rigorously test the hypothesis conveyed by our experimental design, we used a method for distance-based, nonparametric, multivariate analysis of variance as outlined in Anderson (2001a). This nonparametric approach combats problems with multivariate normality, particularly since rare species can often have skewed distributions dominated by zeros. Following the advice of Anderson (2001b), we permuted raw assemblage data 9999 times to produce approximate tests.

The "distance-based" aspect permitted variance partitioning built on appropriate distance measures. Traditional MANOVA implicitly uses Euclidean distance, which is often inappropriate for ecological data because zero values create a "species abundance paradox" (Legendre and Legendre 1998, Legendre and Gallagher 2001) where ecosystems that do not share species may be more similar than ecosystems that share species. Here, we first $\log (X+1)$ transformed species abundance data to stabilize variances. Then, we used the metric Hellinger distance transformation of Legendre and Gallagher (2001) to create the distance matrix, which was later variance-partitioned and ordinated. We also show results of analyses based on the metric Chord distance and nonmetric Bray-Curtis distance, both of which may perform well with similar assemblage data (Legendre and Legendre 1998, Legendre and Gallagher 2001). For comparison, we also included results based on Euclidean distance.

To describe the response by grazer taxa, we used two complementary graphical approaches involving distance-based redundancy analysis (db-RDA). We first reduced dimensionality of species responses to experimental treatments (using Hellinger distance) and created two-dimensional biplots using the RDA routine of CANACO 4.0 (ter Braak and Simaleur 1998). Biplots simultaneously show species response to all of treatments but only in two dimensions at a time. We focused the ordination on relationships between species and treatment vectors (using "RDA scaling type 2"; Legendre and Legendre 1998:586). To help further inter- 


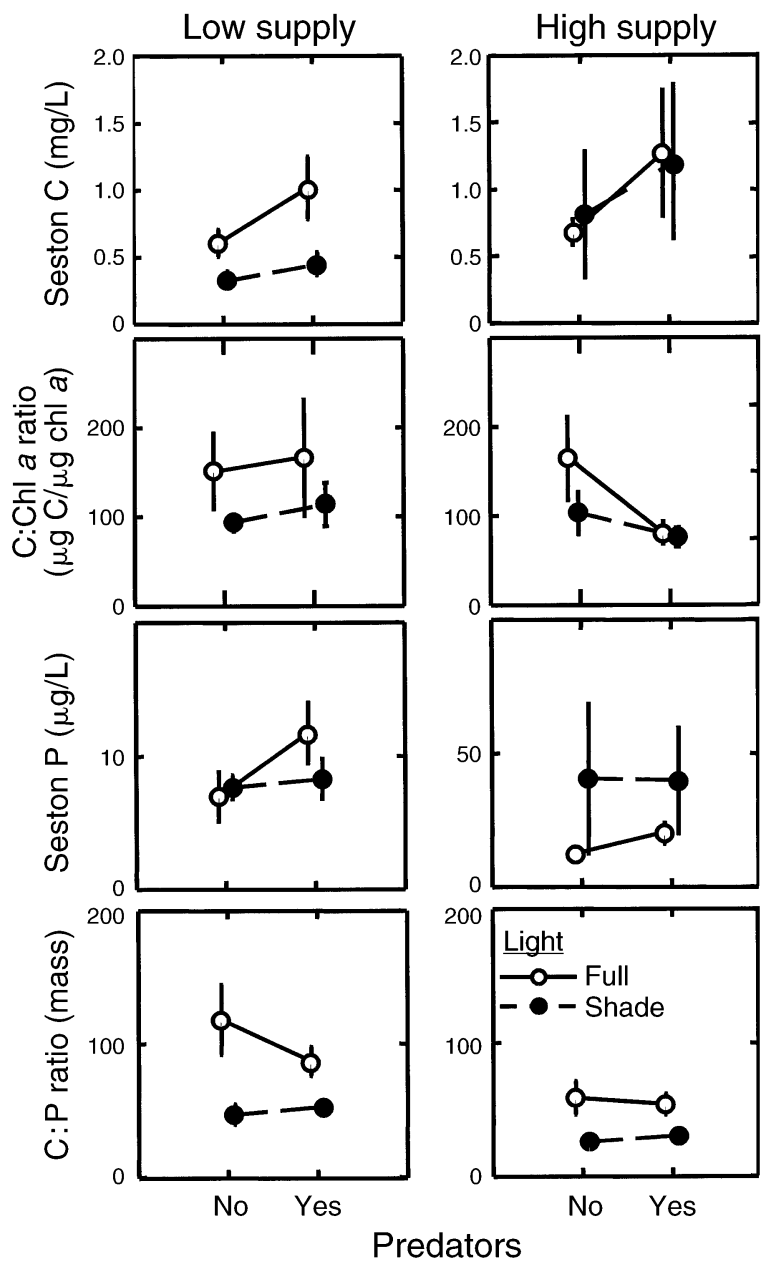

FIG. 1. Response of "edible" seston stoichiometry. Seston carbon (C) responded strongly to the light treatment, seston phosphorus $(\mathrm{P})$ responded strongly to the nutrient-supply treatment, and the C:P ratio responded strongly to the supply and light gradients and weakly to the nutrient ratio gradient. The C:chla ratios are low, indicating that most seston is not detritus. Points are means \pm 1 SE. Note the change in scale of seston P between low- and high-supply treatments.

pret the db-RDA results, we then calculated correlations between species abundance and experimental treatments using all of the orthogonal dimensions from the RDA. This approach shows how species responded to only individual treatments but in all dimensions. Our scaling choice implied that angles between a species vector $(\mathbf{y})$ and an experimental treatment vector $(\mathbf{x})$ reflected the correlation between them $\left(r_{\mathbf{x y}}\right)$. This correlation was estimated using

$$
r_{\mathbf{x y}}=\cos ^{-1}(\theta)=\frac{\mathbf{x} \cdot \mathbf{y}}{|\mathbf{x}||\mathbf{y}|}
$$

where $\theta$ is the angle between $\mathbf{x}$ and $\mathbf{y}$. We plotted correlations between 11 taxa for which we had P data (Fig. 4 and Andersen and Hessen 1991) and significant treatment vectors.

\section{RESULTS}

Seston stoichiometry responded to the light-nutrient-trophic treatments. Seston C was higher in unshaded than in shaded ecosystems (Light effect, $P=$ 0.0001; Appendix A, Fig. 1), and consisted largely of algal matter, based on observed edible $\mathrm{C}$ :chl $a$ ratios (Fig. 1; median $=81.3$, interquartile range: $63.8-141.0$; correlation of $\log (\operatorname{chl} a)-\log (\mathrm{C})$ : Pearson's $r=0.74$, $P<0.0001$ after 99999 randomizations, $N=72$ mesocosms) which fall well within reported ranges for phytoplankton growth at various nutrient and light supplies (Shuter 1979, Geider et al. 1987, 1996). Seston $\mathrm{P}$ was greater in high-nutrient ecosystems than in lownutrient ecosystems (Supply effect, $P<0.0001$; Appendix A, Fig. 1). As a result, both light and nutrient supply drove the C:P ratio response (Appendix A, Fig. 1). Seston $C: P$ ratios were higher (i.e., seston was less $\mathrm{P}$ rich) at low nutrient supply than at high nutrient supply (via a Supply effect on seston P; $P<0.0001$ ) and also were higher at full light than at low light (via a Light effect on seston $\mathrm{C}, P<0.0001$ ). Although nonsignificant after correction for multiple comparisons $(P=0.0354$, Appendix A), seston C:P ratios were generally lower at 5:1 than 50:1 N:P ratios.

Daphnia pulex (hereafter Daphnia) responded strongly to the nutrient-supply and predation-risk manipulations (Fig. 2). In low-P-supply mesocosms, Daphnia comprised $<5 \%$ of zooplankton assemblage biomass in 34 of 36 ecosystems, and this response was

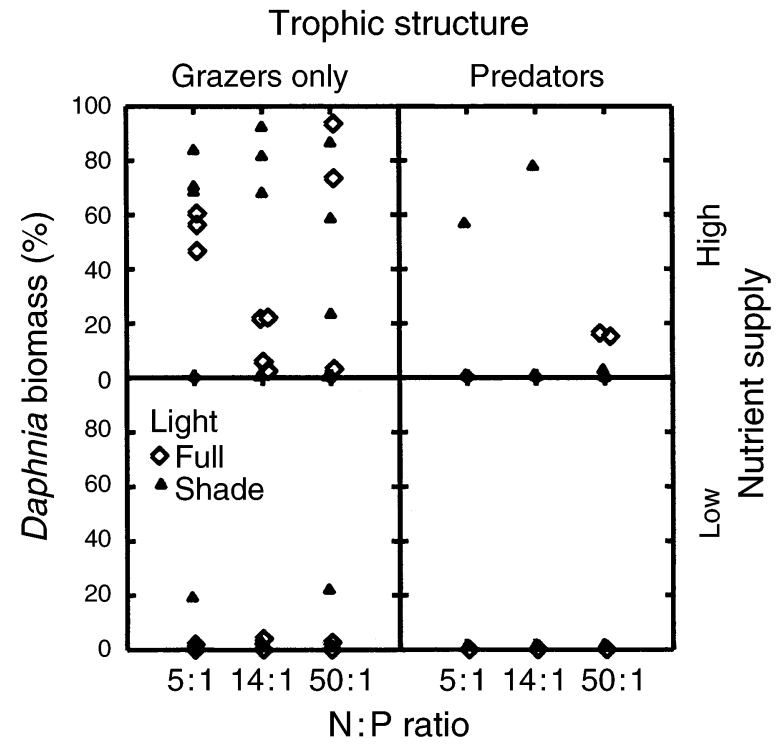

FIG. 2. Response of Daphnia to experimental treatments. An experimental trophic-manipulation treatment comprised "grazer-only" and "predator" treatments, while in the "nutrient-supply" treatment, high-supply mesocosms received 10 times the nutrient loading of low-supply mesocosms. Each point represents a separate mesocosm but is the mean of three sampling dates (no error bars shown). Daphnia biomass is on a percentage basis, relative to the crustacean zooplankton community (dry mass, $\mu \mathrm{g} / \mathrm{L}$ ). 
insensitive to predator incidence (Daphnia were rare, i.e., $<5 \%$ of assemblage biomass, in 16 of 18 mesocosms without predators, and in 18 of 18 mesocosms with predators). In contrast, Daphnia were more commonly dominant in high-nutrient systems. Without predators, Daphnia often (12 of 24 cases) comprised $>50 \%$ of zooplankton assemblage biomass. However, in 7 of 24 of the no-predator tanks, Daphnia constituted $<5 \%$ of total assemblage biomass. In ecosystems with high nutrient supply and with predators, Daphnia comprised $>5 \%$ of assemblage biomass in only 4 of 18 cases.

In predator-free ecosystems, the relationship between Daphnia biomass and seston C:P ratios was $L$ shaped (Fig. 3). At high C:P ratios (P-poor food), Daphnia biomass was low, whereas at low C:P ratios (P-rich food), Daphnia biomass ranged from low to high. Based on tree regression, a C:P ratio of 41.1 by mass (106.2 by moles) separated these regions. However, this response was likely driven by seston $\mathrm{P}$, not seston C (Fig. 3). The response of Daphnia to seston P was also $L$ shaped (or possibly $T$ shaped). At low seston P, biomass of Daphnia was low, whereas past a threshold (7.5 $\mu \mathrm{g}$ particulate P/L), abundance of Daphnia ranged widely (Fig. 3). Generally, seston $\mathrm{P}$ fell below this threshold in low-nutrient mesocosms, whereas most high-nutrient mesocosms had higher seston P (Fig. 3). In contrast, we found no relationship between seston C and abundance of Daphnia (Fig. 3).

\section{Response of the zooplankton assemblage}

Before characterizing the response of the grazer assemblage, we first noted a gradient of body composition among major zooplankton taxa in the experiment (ANOVA of log-transformed P content; $F_{8,24}=46.7, P<$ 0.0001). Although Daphnia generally is given great attention due to its high P content, Daphnia pulex certainly did not have extreme C:P stoichiometry relative to several other co-occurring grazers. Ceriodaphnia, Scapholebris, and Simocephalus had nutrient content similar to or higher than Daphnia. Notably, these grazers are all in the same family (Daphnidae). Like Daphnia, Diaphanasoma and the cyclopoid copepod $\mathrm{Me}$ socyclops also have intermediate nutrient content, while Chydorus, calanoid copepods, and ostracods also had low nutrient content (Fig. 4).

How did these zooplankton taxa respond to the lightnutrient-predation treatments? The distance-based (db), nonparametric (np) MANOVA results were similar based on Hellinger, Bray-Curtis, Chord, and Euclidean distances: Ratio $(P=0.0019)$, Supply $(P<$ $0.0001)$, Light $(P<0.0001)$, and Trophic $(P<0.0001)$ treatments all shaped zooplankton assemblages (Appendix B). Additionally, three interactions were statistically significant: Ratio $\times$ Supply $(P<0.0021)$, Ratio $\times$ Light $(P=0.0009)$, and Supply $\times$ Light $(P<$ 0.0001) (Appendix B). Vectors coding for these seven significant terms in the $\mathrm{db}$, np MANOVA model are
Nutrients, Light

o Low, Full

- Low, Shade

$\square$ High, Full

$\triangle$ High, Shade

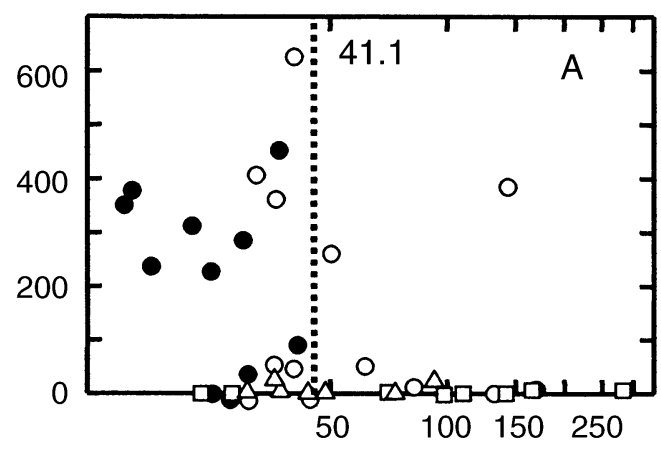

C:P Ratio $(\mu \mathrm{g} \mathrm{C} / \mu \mathrm{g} P)$
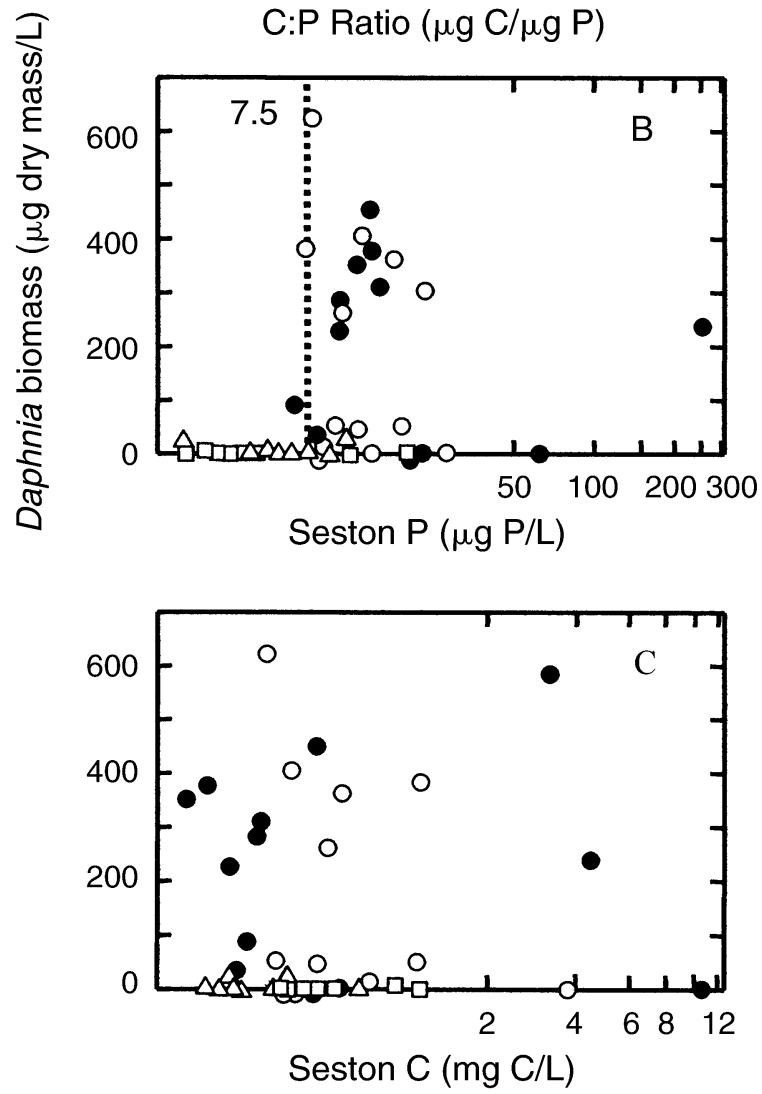

Fig. 3. Relationship between Daphnia biomass and "edible" $(<35 \mu \mathrm{m})$ algal seston stoichiometry for algae + grazer treatments: (A) C:P ratio, (B) particulate $\mathrm{P},(\mathrm{C})$ particulate $\mathrm{C}$. Note the log-scale $x$-axis in (B) and (C). Vertical dashed lines represent values of C:P ratio ( 41.1 by mass), and seston phosphorus $(7.5 \mu \mathrm{g} \mathrm{P} / \mathrm{L})$ that split Daphnia abundance into "lower" and "higher" abundance groups, based on tree regression. 


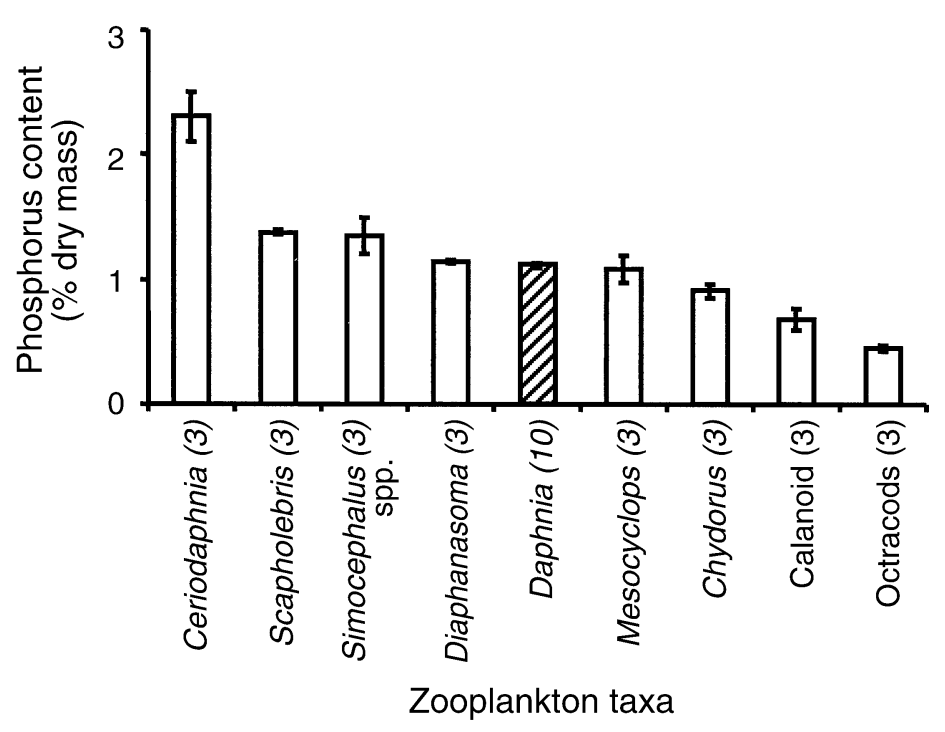

FIG. 4. Measurements of the phosphorus content trait (percentage $\mathrm{P}$ per unit dry mass) for nine abundant taxa in the experiment, ranked from highest to lowest P content. Numbers in parentheses near taxa names are sample sizes. Bars indicate means $\pm 1 \mathrm{SE}$. illustrated in the constrained ordination results (Figs. 5 and 6).

We used both the RDA biplots (Fig. 5) and derivative correlation calculations (Fig. 6) to interpret species responses. First, Daphnia responded most strongly to the high-nutrient (i.e., lower C:P ratio; Fig. 1, Appendix A) and low-predation treatments, but not strongly to the light treatments and nutrient-ratio treatments (which also affected seston C:P ratios; see also Fig. 1, Appendix A). In contrast, other P-rich taxa were more abundant in low-nutrient environments (Ceriodaphnia, Scapholebris, Simocephalus vetulus) and high-light environments (Ceriodaphnia, Diaphanosoma, Scapholebris, Simocephalus vetulus), especially in jointly highlight, low-nutrient environments (Scapholebris and $S$. vetulus; Supply $\times$ Light interaction) or in high-light, high-nutrient environments (Ceriodaphnia, S. serrulatus, Diaphanosoma; Supply $\times$ Light interaction). Furthermore, several of these taxa were more (Ceriodaphnia) or less (Scapholebris, S. serrulatus) proportionately abundant at 50:1 than at $14: 1$ and 5:1 ratio treatments, particularly in high-light environments (both Ratio $\times$ Light interactions) and low-nutrient environments (both Ratio $\times$ Supply interactions).

The constrained ordination also revealed that response of low-P species was idiosyncratic (Figs. 5 and 6). Calanoid copepods were most abundant at low nutrient supply (Supply effect) and at high predation intensity (Trophic effect). Two cladocerans, Chydorus and Bosmina, often responded oppositely; for instance, Chydorus was more abundant in high-nutrient (Supply effect) and low-light (Light effect) environments. In contrast, Bosmina was most abundant at high light and at 5:1 and 14:1 ratios (involving complex Ratio $\times$ Supply and Ratio $\times$ Light interactions), but was not affected by predator incidence. Both Bosmina and Chydorus were less abundant in 50:1 than 14:1 and 5:1 treatments (Ratio effect, Figs. 5 and 6).
Cyclopoid copepods responded uniquely. Several taxa (Acanthocyclops, Diacyclops, Eucyclops, and copepodites) were abundant in low-light environments with nutrients supplied at 50:1 ratios (Fig. 5). However, high correlations with the Ratio $\times$ Supply (all four taxa) and Ratio $\times$ Light (all but Diacyclops) interactions suggested context dependency of these responses (not shown). Mesocyclops was most abundant in the 5: 1 and low-light treatments (Figs. 5 and 6).

\section{Discussion}

We tested current stoichiometric theory linking supply of light and nutrients with changes in the species composition of grazer assemblages via elemental foodquality mechanisms. Our approach differs from previous tests of the "light:nutrient hypothesis" (Sterner et al. 1997, Hessen et al. 2002) because we allowed diverse assemblages of producers and grazer to respond to the light, nutrient, and predation treatments throughout the growing season. As a result, we characterized response of a regional species pool, and not local assemblages alone, to these gradients (Leibold et al. 1997).

The light-nutrient hypothesis predicts that the relative supplies of light and nutrients should drive variation in phosphorus content of edible phytoplankton. This link was observed in our experiment, as C:P ratio of algal seston was higher, and, subsequently, elemental food quality was worse, for grazers in fully lit and lownutrient environments (Fig. 1). However, light and nutrients affected $\mathrm{C}: \mathrm{P}$ ratios differently. Light availability affected $\mathrm{C}$ sequestered in algal tissue, while nutrient supply affected $\mathrm{P}$ sequestered in algal tissue (Fig. 1).

Daphnia responded to this gradient in food quality largely as predicted by the ecological stoichiometrybut with one important nuance. Daphnia dominated grazer assemblages only in predator-free ecosystems with high nutrient-supply rates (Fig. 2). In these en- 


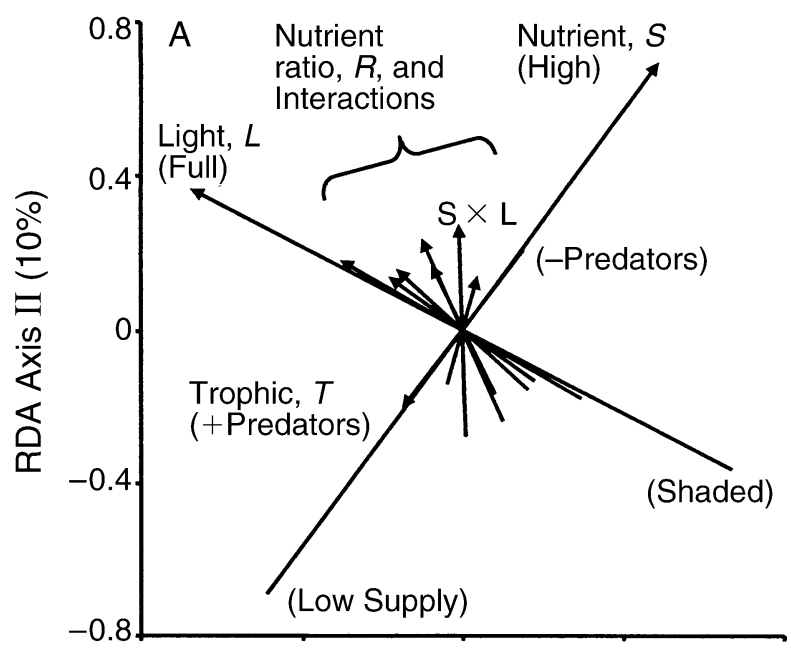

Cladocerans

(a) Alona spp.

(b) Bosmina

(c) Ceriodaphnia*

(d) Chydorus

(e) Daphnia pulex

(f) Diaphanasoma*

(g) Macrothrix

(h) Pleuroxus dentatum

(i) $P$. procurvatus

(j) Scapocephalus serulatus*

(k) Simocephalus serulatus*

(I) S. vetuluts*

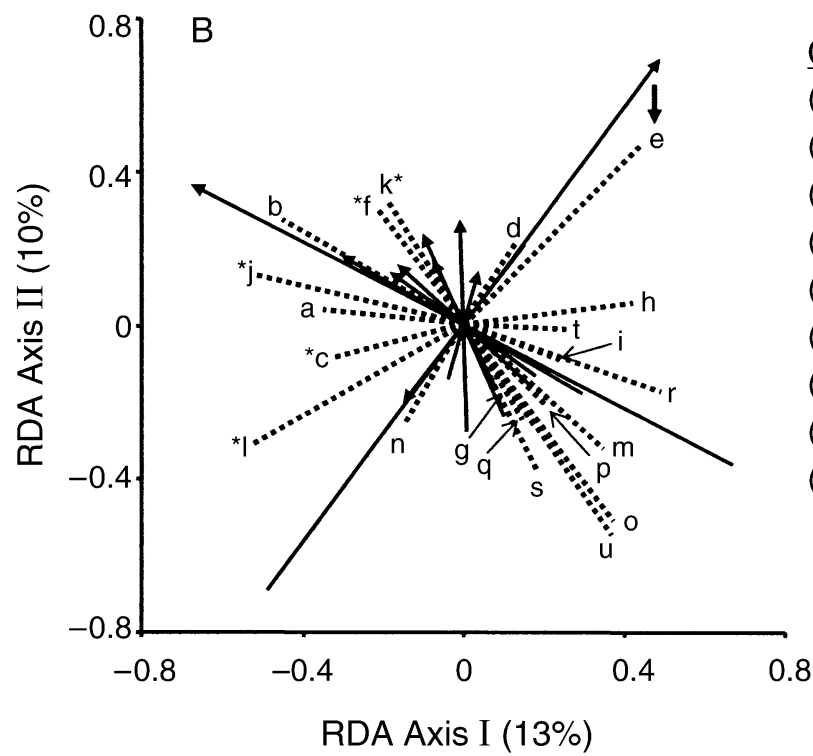

Copepods

(m) Acanthocyclops

(n) Calanoid

(o) Copepodite

(p) Diacyclops

(q) Eucyclops

(r) Mesocyclops

(s) Nauplii

(t) Tropocyclops

(u) Ostracods

RDA Axis I (13\%)

FIG. 5. Biplots of 21 taxon vectors (dashed lines) in relation to vectors representing the statistically significant (Appendix B) treatments (solid arrows). These two-dimensional results follow a constrained ordination using redundancy analysis (RDA; see Methods for details). The ordination is scaled so that the angles between taxon and treatment vectors reflect their correlations: acute angles imply strong positive response of taxon to a treatment; obtuse angles imply a strong negative response. For clarity, treatment vectors are separated from taxon vectors in panel (A); both sets of vectors are combined in panel (B). In the taxa key and in panel (B) the arrow points to Daphnia, and the stars mark five taxa with body P composition similar to or higher than Daphnia. Two vectors code for the Ratio treatment and each of its interactions because there were three levels $(5: 1,14: 1,50: 1)$. The percentage of variance explained by each of the first two RDA axes (analogous to the scaled eigenvalues of the principal components in PCA) is presented in parenthesis in each axis label.

vironments, food quality generally fell below a sestonic $\mathrm{C}: \mathrm{P}$ ratio of 41.1 by mass (106 by moles; Fig. 3 ). Interestingly, this level is lower than critical C:P levels cited in laboratory and theoretical studies of Daphniaonly ecosystems (Urabe and Watanabe 1992, Andersen 1997, Sterner and Elser 2002). However, it appears that Daphnia responded to levels of sequestered P, not sequestered C (Fig. 3). In almost all high-nutrient ecosystems, sequestered algal $\mathrm{P}$ exceeded a threshold (7.5 $\mu \mathrm{g}$ particulate P/L) above which Daphnia could dominate grazer assemblages. Conversely, almost all low- nutrient ecosystems fell below this particulate $\mathrm{P}$ threshold. In these systems, Daphnia was not an important component of grazer assemblages. Consequently, these results suggest that a threshold requirement of sequestered $\mathrm{P}$, rather than a key $\mathrm{C}: \mathrm{P}$ ratio, acted as a determinant of Daphnia dominance.

Predation risk was the other major determinant of abundance of Daphnia. Consistent with previous studies (Scott and Murdoch 1983, Arner et al. 1998), the presence of notonectid predators greatly reduced both the actual and the relative biomass of Daphnia in high- 


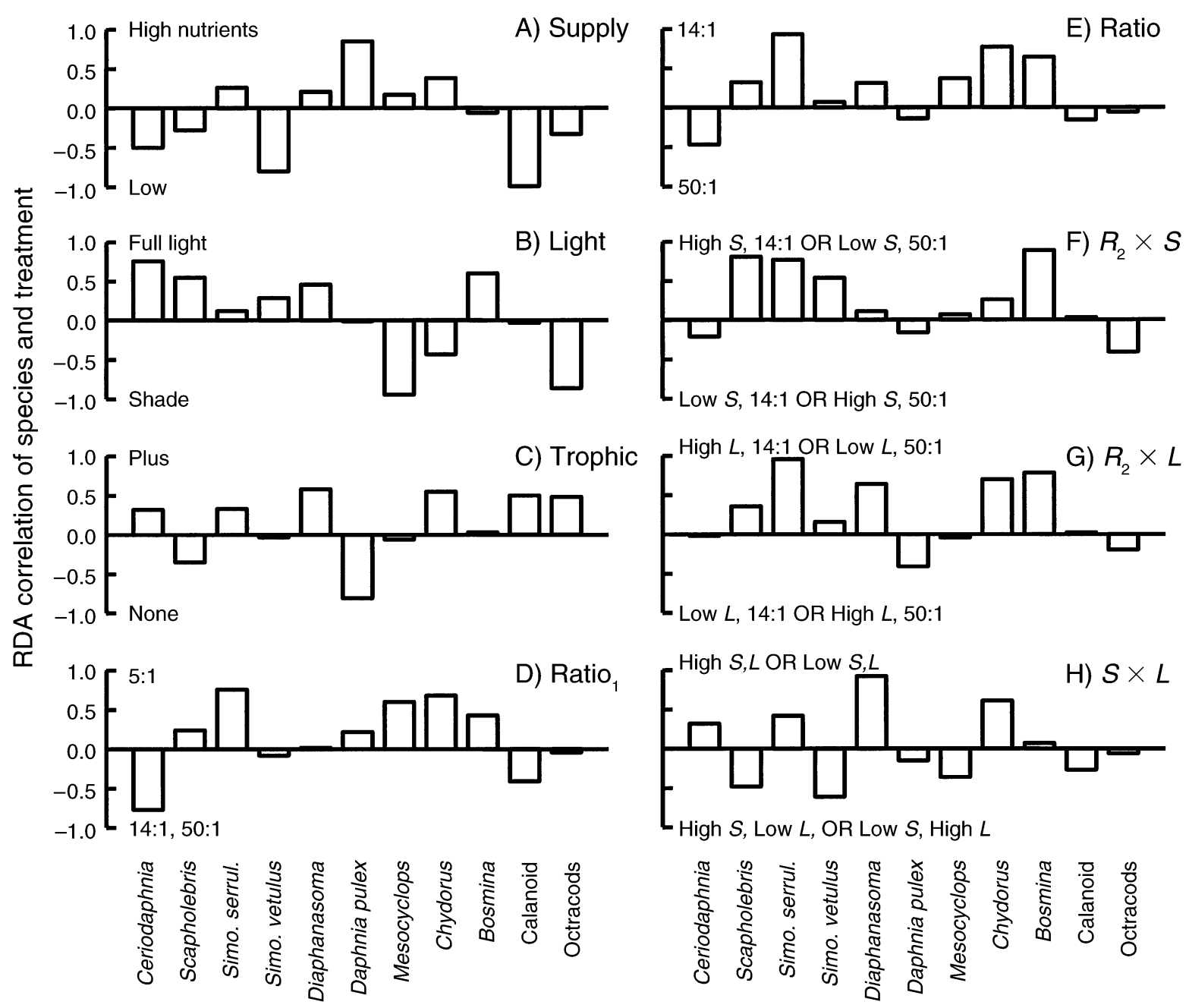

FIG. 6. Multidimensional correlations of 11 taxa for which phosphorus content measurements are available (see Fig. 3). The Bosmina ranking came from Andersen and Hessen (1991), and the two Simocephalus species (serrulatus and vetulus) were assumed to have similar body composition. Taxa are ranked from highest $\mathrm{P}$ content to lowest. Guides for interpreting strong negative and positive correlations are also provided with each panel. Two vectors represent the three levels of the Ratio treatments; therefore each Ratio vector has a subscript. Responses of the taxa to the two vectors representing both the Ratio $(R) \times$ Supply $(S)$ and Ratio $(R) \times$ Light $(L)$ treatments were very similar; hence, only one of the vectors in each interaction is shown.

nutrient ecosystems. However, at low nutrient-supply rates the role of predation in determining Daphnia dominance was negligible. In this treatment, low sequestered P apparently constrained Daphnia abundance-regardless of predator incidence. Superficially, this result resembles predictions of food-web theory, which ignores stoichiometry (e.g., Leibold 1996), but the mechanism here is different. In traditional theory, predators play a minor role at lower nutrient supply because predator biomass is low. Yet, in the case here, prey biomass (Daphnia) remained low regardless of predator incidence (likely) due to stoichiometric (P) constraints. Thus, both predation and food quality shaped zooplankton assemblages through effects on Daphnia, supporting the conceptual model of Elser et al. (1998) of stoichiometry-predation interactions.
Even in environments in which it could flourish (high nutrients, no predators), Daphnia did not always dominate zooplankton assemblages. In $>25 \%$ of the highnutrient, no-predator treatments, Daphnia was a minor or undetectable component of zooplankton assemblages (Fig. 2). This result suggests two possibilities: in high-nutrient ecosystems, relative abundance of Daphnia oscillated asynchronously among mesocosms, or alternative stable states existed. Because we only sampled the experiment at the end of the growing season, we cannot dismiss the oscillatory scenario (although all seven ecosystems had low Daphnia abundance during all three sampling dates). However, stoichiometrically explicit, nonlinear food-chain models (Andersen 1997, Loladze et al. 2000) can predict alternative stable states at high nutrient-supply rates. In these stoichio- 
metrically explicit models, a grazer like Daphnia can either coexist with an edible plant, or it can be driven extinct due to poor food quality. In a model of stoichiometrically explicit grazer competition (Hall, in press), alternative stable states can emerge at intermediate resource supply.

For proponents of ecological stoichiometry, the general response of Daphnia is encouraging because it suggests a link between light:nutrient supply, food quality, and dominance by a P-rich grazer species. Yet, if this mechanism is truly general, other zooplankton taxa (Ceriodaphnia, Scapholebris, Simocephalus, Diaphanosoma; see Fig. 4) with high somatic P content should have responded similarly and consistently to the sestonic C:P gradient (Leibold 1998). However, they did not. In fact, several of these taxa were more abundant in low-nutrient or high-light ecosystems (Figs. 5 and 6). Both of these treatments provided poorer food quality (higher $\mathrm{C}: \mathrm{P}$ ) for grazing herbivores.

At face value, this inconsistency is problematic for stoichiometric theory because the proposed body-composition mechanism failed to correctly predict responses of other high-P species. There are at least two plausible explanations for these results. While they do not contradict stoichiometric principles, they do suggest areas needing further work. First, some grazers may occupy somewhat different feeding niches than Daphnia. For instance, Scapholebris typically feeds upon surface film, so measurements of nutrient content of "seston" from a water column may or may not adequately describe the nutrient content of its diet. However, documented examples of competition between Daphnia and Ceriodaphnia (Neill 1975, Lynch 1978, 1979, Smith and Cooper 1982), Diaphanasoma (Mateev 1987), and Simocephalus (Grover et al. 2000) suggest diet high overlap between Daphnia and other grazers. Yet, zooplankton grazers can differentially use bacterial resources smaller than 1-2 $\mu \mathrm{m}$. For instance, $\mathrm{Cer}$ iodaphnia and Diaphanasoma have finer-mesh filters than Daphnia (Pace et al. 1983). These differences could be important because bacteria typically have higher nutrient content than algae (Elser et al. 1996, Sterner et al. 1998, Sterner and Elser 2002), and thus could provide crucial sources of $P$ for these grazers and not Daphnia. Unfortunately, we did not separate size fractions of seston into bacterial and non-bacterial components, so it is impossible to evaluate this hypothesis with results from our experiment. If bacteria provide important sources of P for some but not other grazers, however, future stoichiometrically explicit models of grazer competition should include bacteria as a food resource and as an interactor with phytoplankton. Furthermore, (in)ability to eat bacteria should be viewed as an important ecological trait of zooplankton in stoichiometric context.

A second, alternative explanation focuses upon determinants of nutrients demands of grazers. Currently, body composition of grazers has gained most attention in stoichiometric experiments and theory (Sterner and Elser 2002), but recent models of stoichiometrically explicit competition among grazers (Loladze et al. 2004; Hall, in press) suggest that this emphasis may be too narrow. These models expand upon a theme that originated in early stoichiometric studies (e.g., Urabe and Watanabe 1992, Hessen 1992; also Sterner 1997, DeMott et al. 1998): other grazer traits, such as conversion efficiency and respiration rate, also determine nutrient demands, and hence competitive ability of grazers for nutrients. Thus, body composition of a grazer solely determines its competitive ability for nutrients only if all other traits are equal. Yet, all other traits among zooplankton species are not equal, and they can vary temporally within an ecosystem and among systems (e.g., Burns 1969, Arnold 1971, Romanovsky and Feniova 1985, Bengtsson 1987, DeMott 1989, Hu and Tessier 1995). Given these differences in traits, theory permits a grazer with higher $\mathrm{P}$ content (e.g., Ceriodaphnia) to outcompete a species with lower P content (e.g., Daphnia) in systems with nutrient-deficient food. Furthermore, if Daphnia is a superior C competitor to such a high $P$ grazer (Gliwicz 1990), these models predict: (1) shifts in species composition from superior nutrient competitors (Ceriodaphnia) to superior C competitors (Daphnia) over a nutrient-supply gradient, and (2) alternative stable states of assemblage structure of grazers (i.e., response of Daphnia in high-nutrient, nopredation treatments; Fig. 2). Both theoretical predictions qualitatively match our otherwise-problematic results. Consequently, they could be explained by stoichiometrically explicit competition theory without invoking hypotheses involving bacteria.

The two main explanations proposed for our challenging experimental results (bacteria as food vs. determinants of competitive ability for nutrients) are not mutually exclusive. Instead, both hypotheses point to areas deserving attention in future stoichiometrically explicit experiments and theoretical efforts. Regardless of the specific explanation, we have documented shifts in grazer composition over resource supply and predation gradients that are consistent with stoichiometric mechanisms. Thus, like the keystone-predation and resource-ratio models, ecological stoichiometry can predict changes in grazer composition over environmental gradients. However, our empirical findings (and companion models) suggest that body composition of grazers should not necessarily be the focal trait in stoichiometric research. Instead, body composition should be combined with other physiologically and ecologically relevant traits to determine a grazer's competitive ability along food-quality gradients driven by resource supply.

\section{ACKNOWLEDGMENTS}

We thank T. Darcy, A. Downing, P. Geddes, and N. Howe for help with sampling, and G. Dwyer, T. Wootton, J. Bergelson, D. Spiller, W. DeMott, and an anonymous reviewer for their comments on the manuscript. We analyzed the C:N 
samples in the Robertson laboratory at Kellogg Biological Station (KBS) with the help of A. Corbin and T. Darcy. Thanks also go to G. Mittelbach, N. Consolatti, A. Tessier, and P. Woodruff at KBS for technical support. M. Bishop of the Michigan DNR permitted us to sample ponds in Barry and Middleville SGAs. Primary funding came from NSF DEB 98-15799 to M. A. Leibold and V. H. Smith. S. R. Hall was also supported by an NSF Graduate Fellowship, a University of Chicago Harper Fellowship and Hinds Fund Award, a Department of Education GAANN training grant, and a NSF DDIG (DEB 01-05014, PI Mathew Leibold). This is KBS contribution number 1128 .

\section{Literature CiTED}

Andersen, T. 1997. Pelagic nutrient cycles: herbivores as sources and sinks. Springer-Verlag, New York, New York, USA.

Andersen, T., and D. O. Hessen. 1991. Carbon, nitrogen, and phosphorus content of freshwater zooplankton. Limnology and Oceanography 36:807-814.

Anderson, M. J. 2001a. A new method for non-parametric multivariate analysis of variance. Austral Ecology 26:3246.

Anderson, M. J. 2001b. Permutation tests for univariate or multivariate analysis of variance and regression. Canadian Journal of Fisheries and Aquatic Sciences 58:629-636.

APHA [American Public Health Association]. 1980. Standard methods for the examination of water and wastewater. Fifteenth edition. American Public Health Association, Washington, D.C., USA.

Arner, M., S. Koivisto, J. Norberg, and N. Kautsky. 1998. Trophic interactions in rockpool food webs: regulation of zooplankton and phytoplankton by Notonecta and Daphnia. Freshwater Biology 39:79-90.

Arnold, D. E. 1971. Ingestion, assimilation, survival, and reproduction by Daphnia pulex fed seven species of bluegreen algae. Limnology and Oceanography 16:906-920.

Bengtsson, J. 1987. Competitive dominance among Cladocera: are single-factor explanations enough? Hydrobiologia 145: $19-28$.

Burns, C. W. 1969. Relation between filtering rate, temperature, and body size in four species of Daphnia. Limnology and Oceanography 14:693-700.

Cottingham, K. L. 1999. Nutrients and zooplankton as multiple stressors of phytoplankton communities: evidence from size structure. Limnology and Oceanography 44:810827.

De'ath, G., and K. E. Fabricius. 2000. Classification and regression trees: a powerful yet simple technique for ecological data analysis. Ecology 81:3178-3192.

DeMott, W. R. 1989. The role of competition in zooplankton succession. Pages 195-254 in U. Sommer, editor. Plankton ecology: succession in plankton communities. SpringerVerlag, New York, New York, USA.

DeMott, W. R., R. D. Gulati, and K. Siewertsen. 1998. Effects of phosphorus-deficient diets on the carbon and phosphorus balance of Daphnia magna. Limnology and Oceanography 43: $1147-1161$.

DeMott, W. R., and A. J. Tessier. 2002. Stoichiometric constraints vs. algal defenses: testing mechanisms of zooplankton food limitation. Ecology 83:3426-3433.

Elser, J. J., T. H. Chrzanowski, R. W. Sterner, and K. H. Mills. 1998. Stoichiometric constraints on food-web dynamics: a whole-lake experiment in the Canadian Shield. Ecosystems 1:120-136.

Elser, J. J., D. R. Dobberfuhl, N. A. MacKay, and J. H. Schampel. 1996. Organism size, life history, and N:P stoichiometry: toward a unified view of cellular and ecosystem processes. BioScience 46:674-684.

Elser, J. J., W. F. Fagan, R. F. Denno, D. R. Dobberfuhl, A. Folarin, A. Huberty, S. Interlandi, S. S. Kilham, E. Mc-
Cauley, K. L. Schulz, E. H. Siemann, and R. W. Sterner. 2000. Nutritional constraints in terrestrial and freshwater food webs. Nature 408:578-580.

Elser, J. J., K. Hayakawa, and J. Urabe. 2001. Nutrient limitation reduced food quality for zooplankton: Daphnia response to seston phosphorus enrichment. Ecology 82:898903.

Geider, R. J., H. L. McIntyre, and T. M. Kana. 1996. A dynamic model of photoadaptation in phytoplankton. Limnology and Oceanography 41:1-15.

Geider, R. J., B. A. Osborne, and J. A. Raven. 1987. Light and temperature dependence of the carbon to chlorophyll $a$ ratio in microalgae and cyanobacteria: implications for physiology and growth of phytoplankton. New Phytologist 106: $1-34$.

Gliwicz, Z. M. 1990. Food thresholds and body size in cladocerans. Nature 343:638-640.

Grover, J. P. 1997. Resource competition. Chapman and Hall, New York, New York, USA.

Grover, J. P., D. McKee, S. Young, H. C. J. Godfray, and P. Turchin. 2000. Periodic dynamics in Daphnia populations: biological interactions and external forcing. Ecology 81: 2781-2798.

Hall, S. R. In press. Stoichiometrically-explicit competition between grazers: species replacement, coexistence, and priority effects along resource supply gradients. American Naturalist.

Hessen, D. O. 1992. Nutrient limitation of zooplankton production. American Naturalist 140:799-814.

Hessen, D. O., P. J. Færøvig, and T. Andersen. 2002. Light, nutrients, and $\mathrm{P}: \mathrm{C}$ ratios in algae: grazer performance related to food quality and quantity. Ecology 83:1886-1898.

$\mathrm{Hu}, \mathrm{S}$. S., and A. J. Tessier. 1995. Seasonal succession and the strength of intra- and interspecific competition in a Daphnia assemblage. Ecology 76:2278-2294.

Huisman, J., and F. J. Weissing. 1995. Competition for nutrients and light in a mixed water column: a theoretical analysis. American Naturalist 146:536-564.

Legendre, P., and E. D. Gallagher. 2001. Ecologically meaningful transformation for ordination of species data. Oecologia 129:271-280.

Legendre, P., and L. Legendre. 1998. Numerical ecology. Elsevier, New York, New York, USA.

Leibold, M. A. 1989. Resource edibility and effects of predators and productivity on consumer-resource interactions. American Naturalist 134:922-949.

Leibold, M. A. 1996. A graphical model of keystone predation: effects of productivity on abundance, incidence, and ecological diversity in communities. American Naturalist 147:784-812.

Leibold, M. A. 1998. Similarity and local co-existence of species in regional biotas. Evolutionary Ecology 12:95110.

Leibold, M. A., J. M. Chase, J. B. Shurin, and A. L. Downing. 1997. Species turnover and the regulation of trophic structure. Annual Review of Ecology and Systematics 28:467494.

Loladze, I., Y. Kuang, and J. J. Elser. 2000. Stoichiometry in producer-grazer systems: linking energy flow with element cycling. Bulletin of Mathematical Biology 62:11371162.

Loladze, I., Y. Kuang, J. J. Elser, and W. F. Fagan. 2004. Coexistence of two predators on one prey mediated by stoichiometry. Theoretical Population Biology 65:1-15.

Lynch, M. 1978. Complex interactions between natural coexploiters Daphnia and Ceriodaphnia. Ecology 59:552-564.

Lynch, M. 1979. Predation, competition, and zooplankton community structure: an experimental study. Limnology and Oceanography 24:253-272. 
Main, T. M., D. R. Dobberfuhl, and J. J. Elser. 1997. N:P stoichiometry and ontogeny of crustacean zooplankton: a test of the growth rate hypothesis. Limnology and Oceanography 42:1474-1478.

Mateev, V. F. 1987. Effects of competition on the demography of planktonic cladocerans-Daphnia and Diaphanasoma. Oecologia 74:468-477.

MathWorks. 1999. Matlab 5. 3: the language of technical computing. The MathWorks, Natick, Massachusetts, USA.

McCauley, E. 1984. The estimation of the abundance and biomass of zooplankton in samples. Pages 228-265 in J. A. Downing and F. H. Rigler, editors. A manual on methods for the assessment of secondary productivity in fresh waters. Blackwell Scientific, Oxford, UK.

Neill, W. E. 1975. Experimental studies of microcrustacean composition and efficiency of resource utilization. Ecology 56:809-826.

Pace, M. L., K. G. Porter, and Y. S. Feig. 1983. Species- and age-specific differences in bacterial resource utilization by two co-occurring cladocerans. Ecology 64:1145-1156.

Pennak, R. W. 1978. Fresh-water invertebrates of the United States. Second edition. John Wiley \& Sons, New York, New York, USA.

Prepas, E. E., and F. H. Rigler. 1982. Improvements in quantifying the phosphorus concentration in lake water. Canadian Journal of Fisheries and Aquatic Sciences 39:822829.

Romanovsky, Y. E., and I. V. Feniova. 1985. Competition among Cladocera: effects of different levels of food supply. Oikos 44:243-252.

Scott, M. A., and W. W. Murdoch. 1983. Selective predation by the backswimmer, Notonecta. Limnology and Oceanography 28:352-366.

Shuter, B. 1979. A model of physiological adaptation in unicellular algae. Journal of Theoretical Biology 78:519-552.

Smith, D. W., and S. D. Cooper. 1982. Competition among Cladocera. Ecology 63:1004-1015.

SPSS. 1998. SYSTAT 8.0 for Windows: statistics. SPSS, Chicago, Illinois, USA.

Sterner, R. W. 1993. Daphnia growth on varying quality of Scenedesmus: mineral limitation of zooplankton. Ecology 74:2351-2360.

Sterner, R. W. 1994. Thresholds for growth in Daphnia magna with high and low phosphorus diets. Limnology and Oceanography 39:1228-1232.
Sterner, R. W. 1997. Modelling interactions of food quality and quantity in homeostatic consumers. Freshwater Biology 38:473-481.

Sterner, R. W., J. Clausen, W. Lampert, and T. Weisse. 1998. Carbon:phosphorus stoichiometry and food-chain production. Ecology Letters 1:146-150.

Sterner, R. W., and J. J. Elser. 2002. Ecological stoichiometry: the biology of element from molecules to the biosphere. Princeton University Press, Princeton, New Jersey, USA.

Sterner, R. W., J. J. Elser, E. J. Fee, S. J. Guilford, and T. H. Chrzanowski. 1997. The light:nutrient relation in lakes: the balance of energy and materials affects ecosystem structure and process. American Naturalist 150:663-684.

Taylor, L. R. 1961. Aggregation, variance, and the mean. Nature 187:732-735.

ter Braak, C. J. F., and P. Simaleur. 1998. CANOCO release 4 reference manual and user's guide to CANOCO for Windows-software for canonical community ordination. Microcomputer Power, Ithaca, New York, USA.

Tilman, D. 1982. Resource competition and community structure. Princeton University Press, Princeton, New Jersey, USA.

Urabe, J., M. Kyle, W. Makino, T. Yoshida, T. Andersen, and J. J. Elser. 2002. Reduced light increases herbivore production due to stoichiometric effects of light/nutrient balance. Ecology 83:619-627.

Urabe, J., and R. W. Sterner. 1996. Regulation of herbivore growth by the balance of light and nutrients. Proceedings of the National Academy of Sciences (USA) 93:84658469.

Urabe, J., and Y. Watanabe. 1992. Possibility of N or P limitation for planktonic cladocerans: an experimental test. Limnology and Oceanography 37:244-251.

Webb, D. J., B. K. Burnison, A. M. Trimbee, and E. E. Prepas. 1992. Comparison of chlorophyll $a$ extractions with ethanol with dimethyl sulfoxide/acetone, and a concern about spectrophotometric phaeopigment correction. Canadian Journal of Fisheries and Aquatic Sciences 49:2331-2336.

Welschmeyer, N. A. 1994. Fluorometric analysis of chlorophyll $a$ in the presence of chlorophyll $b$ and pheopigments. Limnology and Oceanography 39:1985-1992.

\section{APPENDIX A}

A table presenting results of nonparametric univariate analyses of edible seston $\mathrm{C}, \mathrm{P}$, and $\mathrm{C}: \mathrm{P}$ ratio is available in ESA's Electronic Data Archive: Ecological Archives E085-068-A1.

\section{APPENDIX B}

A table presenting results of nonparametric, Hellinger distance-based MANOVA of zooplankton community-composition response to the treatments, using Anderson's $(2001 a, b)$ method, is available in ESA's Electronic Data Archive: Ecological Archives E085-068-A2. 